See Article page 1.

\section{Commentary: Covert or overt? Depends on how hard you look}

\author{
Berhane Worku, MD, and \\ Mario Gaudino, MD, MSCE
}

Stroke remains the Achilles heel of coronary artery bypass grafting (CABG). CABG studies not specifically designated to look at perioperative stroke likely underestimate the incidence of this complication due to ascertainment issues and the competing risk of death. ${ }^{1,2}$

In the current article Browne and colleagues ${ }^{3}$ analyze the association of covert stroke (asymptomatic acute infarcts on magnetic resonance imaging [MRI]) after CABG with intraoperative cerebral oxygen desaturation events and postoperative cognitive function. Of the 49 of 66 patients who completed an MRI and had interpretable images, $39 \%$ had a covert stroke and $6 \%$ a clinical stroke. Cerebral oxygen desaturation events were twice as common in patients with covert stroke $(67 \%$ vs $32 \% ; P=.02)$. Postoperative delirium occurred in $26 \%$ of patients with compared with $10 \%$ of those without covert stroke. The analysis was performed as a feasibility study for future large multicenter prospective studies of covert stroke after CABG. ${ }^{3}$ Such a study would be both valuable and, as the current study suggests, feasible.

Strategies to prevent perioperative stroke have focused on minimizing aortic manipulation, as this has been demonstrated to correlate with both overt and covert stroke rates. ${ }^{4,5}$ Randomized trials of off-pump CABG have not demonstrated a benefit with regards to stroke, ${ }^{6-8}$ cognitive outcomes, ${ }^{7,9}$ or mortality. ${ }^{6-8}$ However, off-pump CABG with the use of lateral aortic clamping does not reduce aortic manipulation and in these trials the off-pump technique was not defined by protocol. Any large-scale study proposing to assess the impact of covert stroke on cognitive function after $\mathrm{CABG}$ should

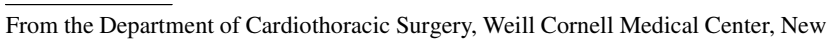
York, NY.

Disclosures: The authors reported no conflicts of interest.

The Journal policy requires editors and reviewers to disclose conflicts of interest and to decline handling or reviewing manuscripts for which they may have a conflict of interest. The editors and reviewers of this article have no conflicts of interest.

Received for publication Aug 27, 2020; revisions received Aug 27, 2020; accepted for publication Aug 28, 2020; available ahead of print Oct 20, 2020.

Address for reprints: Mario Gaudino, MD, MSCE, Department of Cardiothoracic Surgery, Weill Cornell Medical Center, 525 East 68th St, M-404, New York, NY 10065 (E-mail: mfg9004@med.cornell.edu).

JTCVS Open 2020;4:12-3

2666-2736

Copyright $@ 2020$ The Authors. Published by Elsevier Inc. on behalf of The American Association for Thoracic Surgery. This is an open access article under the CC BY-NCND license (http://creativecommons.org/licenses/by-nc-nd/4.0/).

https://doi.org/10.1016/j.xjon.2020.08.017
Check for updates

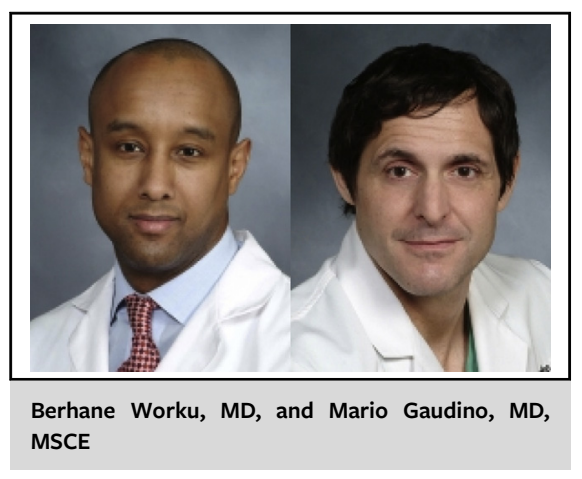

CENTRAL MESSAGE

Covert stroke after CABG is an underappreciated phenomenon and likely related to the degree of aortic manipulation. Any correlation with cognitive outcomes will require rigorous assessment to discern.

consider incorporating an analysis of such techniques. In addition, cognitive outcomes likely correlate with the number and size of new lesions, not simply their presence, similar to that seen after transcatheter aortic valve replacement (TAVR). ${ }^{10,11}$ Therefore, accurate assessment of lesion burden is mandatory, and preoperative MRI should be considered to control for the degree of baseline cerebral lesion burden.

The experience with cerebral protection devices during TAVR has taught us that debris is liberated from the aorta/ aortic valve complex in all such procedures, with the majority of patients demonstrating radiographic infarcts on MRI. ${ }^{10,11}$ This is analogous to the presence of "hits" on transcranial Doppler ultrasonography ubiquitously noted during $\mathrm{CABG}$ at the time of aortic manipulation. ${ }^{12}$ What is more difficult to measure is the cognitive effect of these embolic events. Perhaps "delirium" is a more sensitive marker of covert stroke than elaborate neurocognitive assessment batteries. ${ }^{3,12}$ Perhaps the effect of the emboli is more evident in older patients? If we could identify the clinical relevance of these "covert" strokes, implications for surgical conduct would be tremendous. Anaortic techniques during CABG may be required to yield "covert" stroke rates comparable with percutaneous interventions. Perhaps cerebral protection devices will find their place in cardiac surgery as they have in TAVR. ${ }^{13}$ What is clear is that aortic manipulation leads to cerebral injury. Whether this injury is covert or overt is a matter of how hard we look. 


\section{References}

1. Mäkikallio T, Holm NR, Lindsay M, Spence MS, Erglis A, Menown IB, et al. Percutaneous coronary angioplasty versus coronary artery bypass grafting in treatment of unprotected left main stenosis (NOBLE): a prospective, randomised, open-label, non-inferiority trial. Lancet. 2016;388:2743-52.

2. Stone GW, Sabik JF, Serruys PW, Simonton CA, Généreux P, Puskas J, et al. Everolimus-eluting stents or bypass surgery for left main coronary artery disease. N Engl J Med. 2016;375:2223-35.

3. Browne A, Spence J, Power P, Copland I, Mian R, Gagnon S, et al. Perioperative covert stroke in patients undergoing coronary artery bypass graft surgery. J Thorac Cardiovasc Surg Open. 2020;4:1-11.

4. Zhao DF, Edelman JJ, Seco M, Bannon PG, Wilson MK, Byrom MJ, et al. Coronary artery bypass grafting with and without manipulation of the ascending aorta. A network meta-analysis. J Am Coll Cardiol. 2017;69:924-36.

5. Tachibana H, Hiraoka A, Saito K, Naito Y, Chikazawa G, Tamura K, et al. Incidence and impact of silent brain lesions after coronary artery bypass grafting. $J$ Thorac Cardiovasc Surg. October 16, 2019 [Epub ahead of print].

6. Lamy A, Devereaux PJ, Prabhakaran D, Taggart DP, Hu S, Paolasso E, et al. Offpump or on-pump coronary-artery bypass grafting at 30 days. $N$ Engl J Med. 2012;366:1489-97.

7. Shroyer AL, Grover FL, Hattler B, Collins JF, McDonald GO, Kozora E, et al; Veterans Affairs Randomized On/Off Bypass (ROOBY) Study Group.
On-pump versus off-pump coronary-artery bypass surgery. $N$ Engl J Med. 2009;361:1827-37.

8. Diegeler A, Börgermann J, Kappert U, Breuer M, Böning A, Ursulescu A, et al; GOPCABE Study Group. Off-pump versus on-pump coronary-artery bypass grafting in elderly patients. N Engl J Med. 2013;368:1189-98.

9. Lamy A, Devereaux PJ, Prabhakaran D, Taggart DP, Hu S, Paolasso E, et al. Effects of off-pump and on-pump coronary-artery bypass grafting at 1 year. $N$ Engl J Med. 2013;368:1179-88.

10. Kapadia SR, Kodali S, Makkar R, Mehran R, Lazar RM, Zivadinov R, et al. Protection against cerebral embolism during transcatheter aortic valve replacement. J Am Coll Cardiol. 2017;69:367-77.

11. Haussig S, Mangner N, Dwyer MG, Lehmkuhl L, Lucke C, Woitek F, et al. Effect of a cerebral protection device on brain lesions following transcatheter aortic valve implantation in patients with severe aortic stenosis. The CLEAN-TAVI randomized clinical trial. JAMA. 2016;316:592-601.

12. Halkos ME, Anderson A, Binongo JNG, Stringer A, Lasanajak Y, Thourani VH, et al. Operative strategies to reduce cerebral embolic events during on- and offpump coronary artery bypass surgery: a stratified, prospective randomized trial. $J$ Thorac Cardiovasc Surg. 2017;154:1278-85.

13. Mack MJ, Acker MA, Gelijns AC, Overbey JR, Parides MK, Browndyke JN, et al. Effect of cerebral embolic protection devices on CNS infarction in surgical aortic valve replacement. JAMA. 2017;318:536-47. 